\title{
The coarsening effect of SA508-3 steel used as heavy forgings material
}

\author{
Dong Dingqian, Cui Zhenshan ${ }^{\mathrm{a}}$, and Liu Mingxiang \\ National ERC for Die \& Mold CAD, Shanghai Jiao Tong University, 200030 Shanghai, China
}

\begin{abstract}
SA508Gr.3 steel is popularly used to produce core unit of nuclear power reactors due to its outstanding ability of anti-neutron irradiation and good fracture toughness. The forging process takes important role in manufacturing to refine the grain size and improve the material properties. But due to their huge size, heavy forgings cannot be cooled down quickly, and the refined grains usually have long time to grow in high temperature conditions. If the forging process is not adequately scheduled or implemented, very large grains up to millimetres in size may be found in this steel and cannot be eliminated in the subsequent heat treatment. To fix the condition which may causes the coarsening of the steel, hot upsetting experiments in the industrial production environment were performed under different working conditions and the corresponding grain sizes were measured and analysed. The observation showed that the grain will abnormally grow if the deformation is less than a critical value. The strain energy takes a critical role in the grain evolution. If dynamic recrystallization consumes the strain energy as much as possible, the normal grains will be obtained. While if not, the stored strain energy will promote abnormal growth of the grains.
\end{abstract}

\section{Introduction}

The increasing energy demand has promoted the construction of higher performance and larger scale energy equipment, which inevitably desires development of manufacturing technology as well as material for high quality large forgings as the key components of the plant [1]. SA508 Gr.3 steel is an alloy widely used in nuclear reactor pressure vessels (RPV) and steam generators (SG) due to its excellent properties such as anti-neutron irradiation and good fracture toughness. Usually, the forgings are very large whose wall thickness can even reach $700 \mathrm{~mm}$ [2]. Thus, the forgings often take a long time to cool down after hot forming, giving grain a favorable opportunity for growth. In addition, for the cooling conditions change significantly from surface to center, the microstructure may varies with the positions, causing gradients of microstructure and mechanical properties [3-5]. Actually, partial grain coarsening is the common defects occurring during the forming of heavy forgings. Some research has been done to explore the relationship between the forming process and microstructure [6-8]. But it is far enough to clearly understand the impact of working parameters on the final microstructure.

Although previous works have made great efforts to improve the application of the material, there are still some restrictions that impede the production of the good performance components. In the

\footnotetext{
${ }^{\text {a }}$ Corresponding author: cuizs@sjtu.edu.cn
}

This is an Open Access article distributed under the terms of the Creative Commons Attribution License 4.0, which permits unrestricted use, distribution, and reproduction in any medium, provided the original work is properly cited. 
Table 1. Composition of SA508 Gr.3 steel (wt.\%).

\begin{tabular}{ccccccccccccccc}
\hline $\mathrm{C}$ & $\mathrm{Mn}$ & $\mathrm{Ni}$ & $\mathrm{Cr}$ & $\mathrm{Mo}$ & $\mathrm{V}$ & $\mathrm{Si}$ & $\mathrm{Al}$ & $\mathrm{N}$ & $\mathrm{P}$ & $\mathrm{S}$ & $\mathrm{Cu}$ & $\mathrm{As}$ & $\mathrm{Co}$ & $\mathrm{Fe}$ \\
\hline 0.18 & 1.4 & 0.79 & 0.14 & 0.51 & 0.005 & 0.22 & 0.024 & 0.0123 & 0.005 & 0.003 & 0.04 & 0.004 & 0.008 & Balance \\
\hline
\end{tabular}

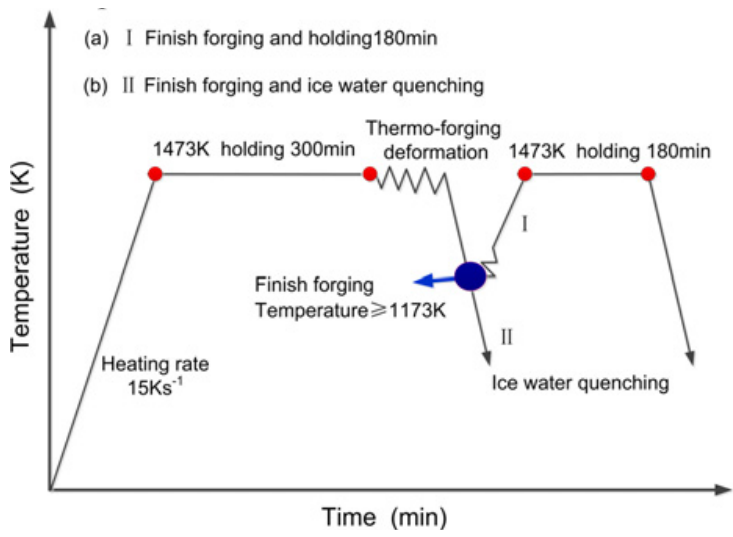

(a) deformation schedule

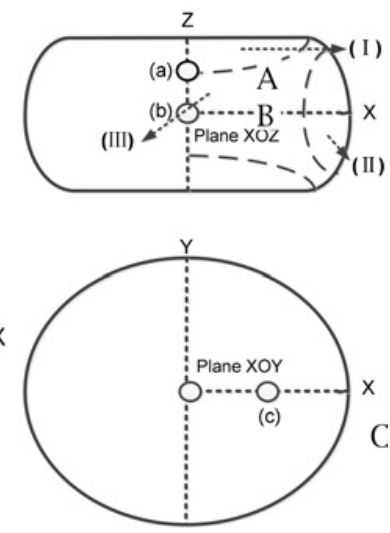

(b) locations to observe grains

Figure 1. (a) The schedule of hot deformation process and (b) locations to observe grains.

long time cooling process of the material after forging, the recrystallized grain coarsening phenomenon easily occurs if the inappropriate forging scheme is implemented, resulting in deterioration of the steel mechanical properties. At present, there are few researches paying attentions in this field [9]. And the mechanism of dynamically recrystallized grain coarsening is not yet clear. Therefore, further research need to be carried out.

Our work aimed to study the grain coarsening mechanism of SA508 Gr.3 steel after hot forging, and try to fix the condition which may cause the coarsening of the steel so as to provide the basis for designing process parameters for large forgings.

\section{Experiments}

The material used is commercial SA508 Gr.3 steel, whose chemical composition is listed in Table 1.

In order to investigate the mechanism of grain coarsening, hot upsetting experiments in the industrial production environment were performed. Cylinder specimens with a diameter of $40 \mathrm{~mm}$ and a height of $60 \mathrm{~mm}$ were heated to $1200{ }^{\circ} \mathrm{C}$ at a heating rate of $15^{\circ} \mathrm{C} / \mathrm{s}$ and held for $300 \mathrm{~min}$ to obtain a homogeneous initial temperature by using the vacuum furnace. The holding time is so long because that in engineering practice, the heavy forgings usually undertake very long heating time and the grains have long time to grow. Then, they were deformed by using 320-ton hydraulic press at a ram speed of $2 \mathrm{~mm} / \mathrm{s}$ till $10 \%$, $15 \%, 20 \%, 40 \%$ and $80 \%$ of reduction were reached, respectively. Two groups of tests were carried out to analyze the coarsening effect as is illustrated in Fig. 1(a). In the first group, the specimens after deformation were quenched into cold water immediately. While in the second group, they were reheated to $1200^{\circ} \mathrm{C}$ and held for $180 \mathrm{~min}$, and then quenched. The microstructures of three different locations, as shown in Fig. 1(b), in each specimen were observed in optical microscope.

Specimens were heated in a box-type electric resistance furnace with a thermocouple feedback system, whose chamber was evacuated to a vacuum of approximately $0.05 \mathrm{~Pa}$ to avoid surface oxidation and decarburization. The quenched specimens were sliced along the axial section, and etched in 

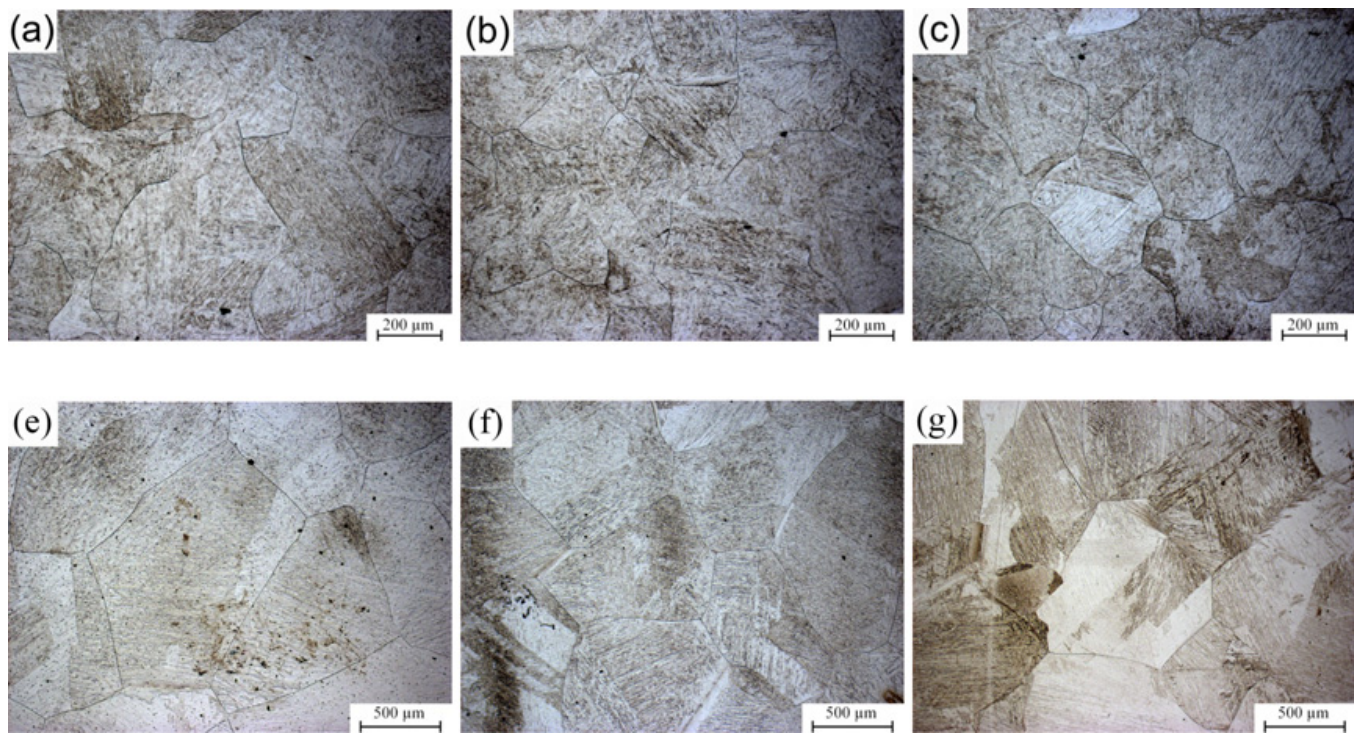

Figure 2. Microstructures of SA508 Gr.3 steel quenched directly (a),(b),(c) and held for 3h (e),(f),(g) after deformation with $10 \%$ reduction.

(5g saturated picric acid $+4 \mathrm{~g}$ SDBS $+100 \mathrm{~mL} \mathrm{H} 2 \mathrm{O}$ ) solution at $65 \pm 5^{\circ} \mathrm{C}$ for 10 s to 60 s to reveal austenite grain boundaries. Microstructure was observed using Zeiss optical microscope. The grain size was determined by using the line intercept method in two vertical directions as per ASTM E112-88.

\section{Results and discussion}

\subsection{The fact of grain coarsening}

Microstructures at three different points of the sample quenched directly (the first group samples) are displayed sequentially and compared to the ones held at $1200{ }^{\circ} \mathrm{C}$ for $3 \mathrm{hrs}$ after deformation (the second group samples), as shown in Fig. 2 thru Fig. 5, respectively corresponding to 10\%, 20\%, 40\% and 80\% reduction. In order to explain the observed results, one needs to notice that the point $\mathrm{A}$ is in the hard deformation region while point $\mathrm{B}$ and $\mathrm{C}$ are in the easy deformation region. Dynamic recrystallization didn't occur when reduction was $10 \%$ and $15 \%$, and no grain refinement was observed in the first group samples, and the second group samples received very large grains, with some of the grains were beyond $1.5 \mathrm{~mm}$ in size. When reduction was $20 \%$, the grains of the first group samples were partially refined, and the grains of the second group samples were also large but were smaller than the ones observed in Fig. 2. When reduction was $40 \%$, the grains at point $\mathrm{B}$ and $\mathrm{C}$ were refined by dynamic recrystallization, while point $\mathrm{A}$ was partially refined because the point located in the hard deformation zone and the dynamic recrystallization was not complete. In this case, the grains at point A and B of the second group samples were normal large with much smaller size than the ones observed when reduction was smaller, but the grains at point $\mathrm{C}$ were still very large. When the reduction was $80 \%$, the grains of the first group samples were well refined by the dynamic recrystallization, while the grains of the second group samples were normal large at point A, but larger at point B and C. No matter the sample has $10 \%$ reduction or $80 \%$ reduction, it can be seen clearly that the grain size increases significantly after being held at high temperature for $3 \mathrm{hrs}$. But the coarsening grain seems to be smaller in $80 \%$ reduction. Among the three sample points, the amount of deformation at point $\mathrm{A}$ is smaller than at point $\mathrm{B}$ (see Fig. 1). By comparing the morphologies of the coarsening grains at point $\mathrm{A}$ and $\mathrm{B}$, it is found that small 


\section{MATEC Web of Conferences}
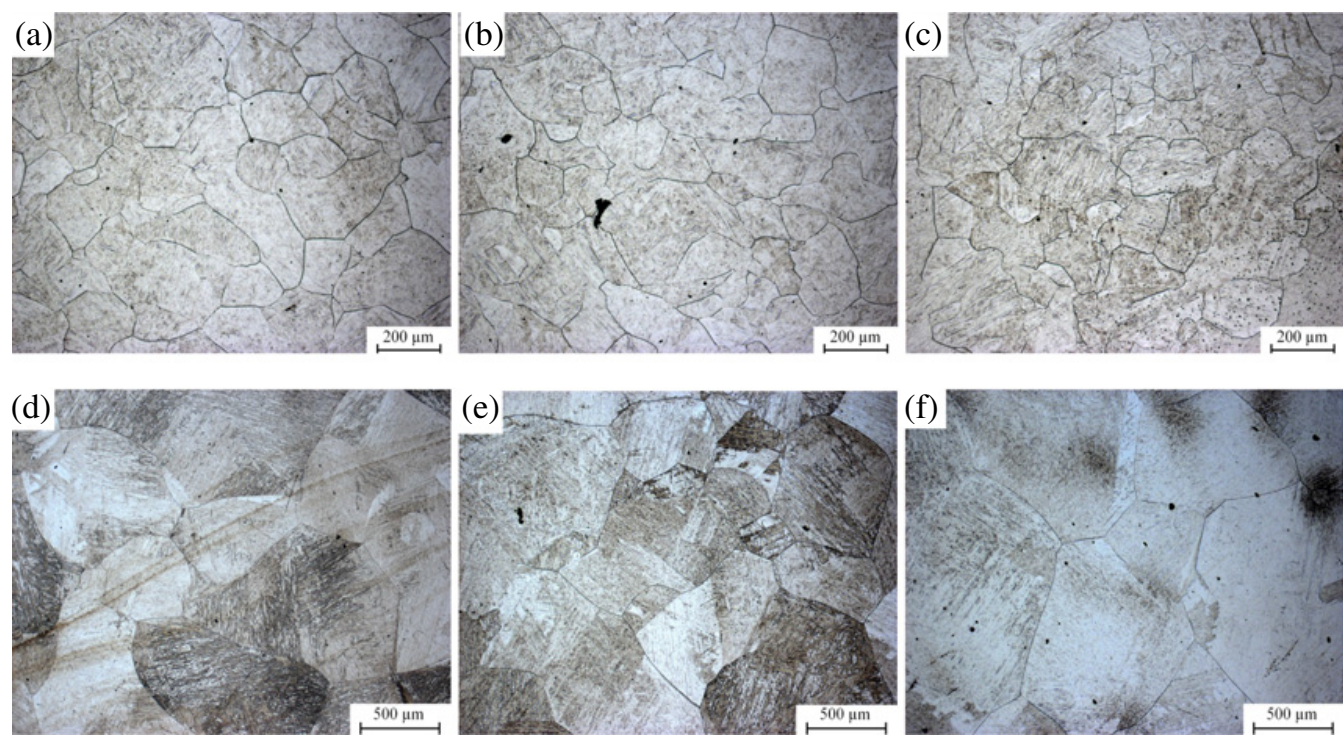

Figure 3. Microstructures of SA508 Gr.3 steel quenched directly (a),(b),(c) and held for $3 \mathrm{~h}$ (e),(f),(g) after deformation with $20 \%$ reduction.
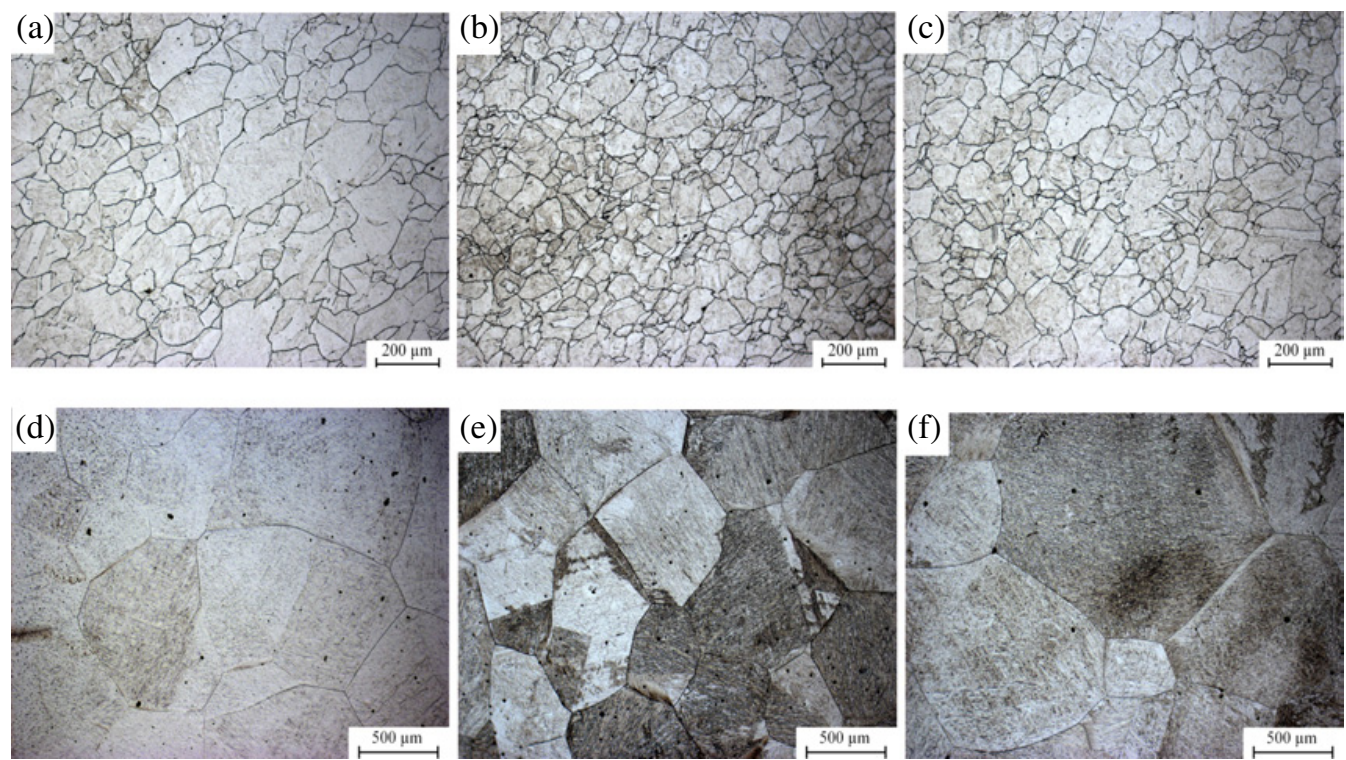

Figure 4. Microstructures of SA508 Gr.3 steel quenched directly (a),(b),(c) and held for $3 \mathrm{~h}$ (e),(f),(g) after deformation with $40 \%$ reduction.

deformation (corresponding strain is smaller than a critical value) may causes bigger coarsening grains in the subsequent high temperature environment, for example, the grain size in Fig. 2(e) may reach $1.5 \mathrm{~mm}$, but it is about $400 \mu \mathrm{m} \sim 600 \mu \mathrm{m}$ in Fig. 4. However, very large deformation may also causes large grains, as observed in Fig. 4(c) and Fig. 5(b) and (c). 

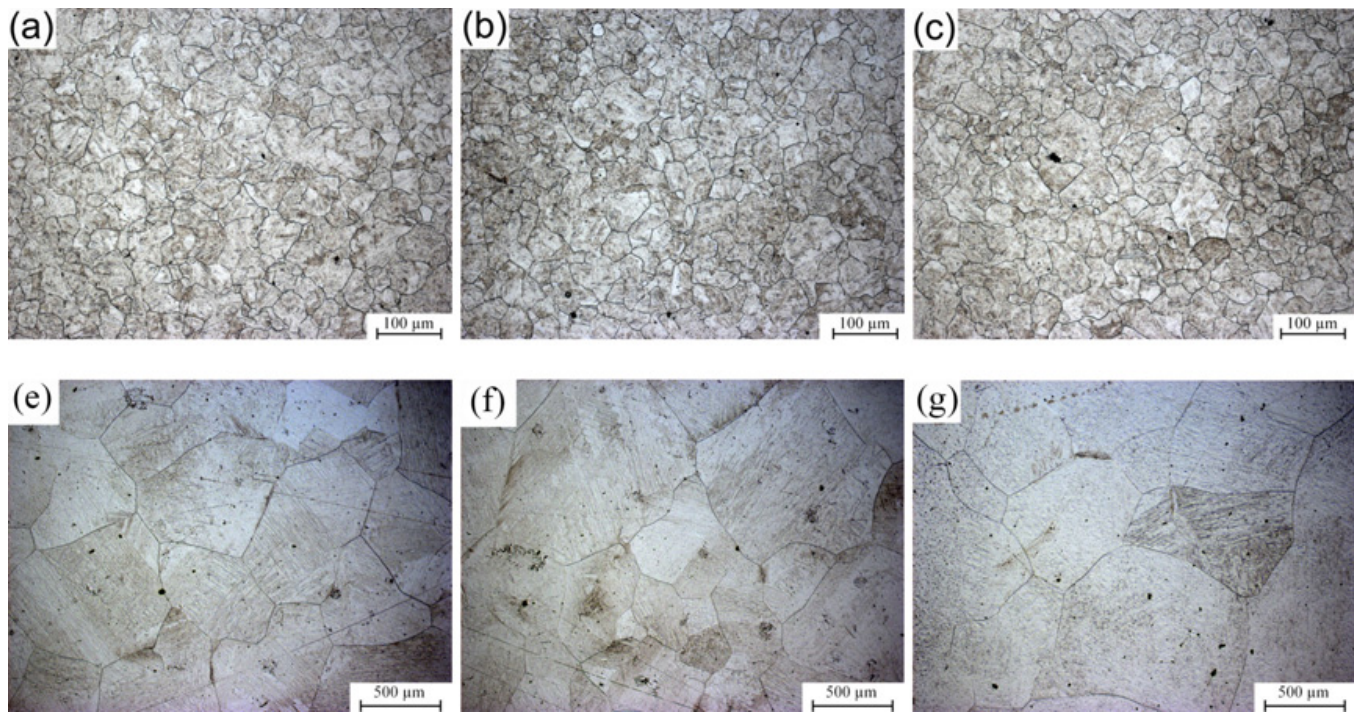

Figure 5. Microstructures of SA508 Gr.3 steel quenched directly (a),(b),(c) and held for 3h (e),(f),(g) after deformation with $80 \%$ reduction.

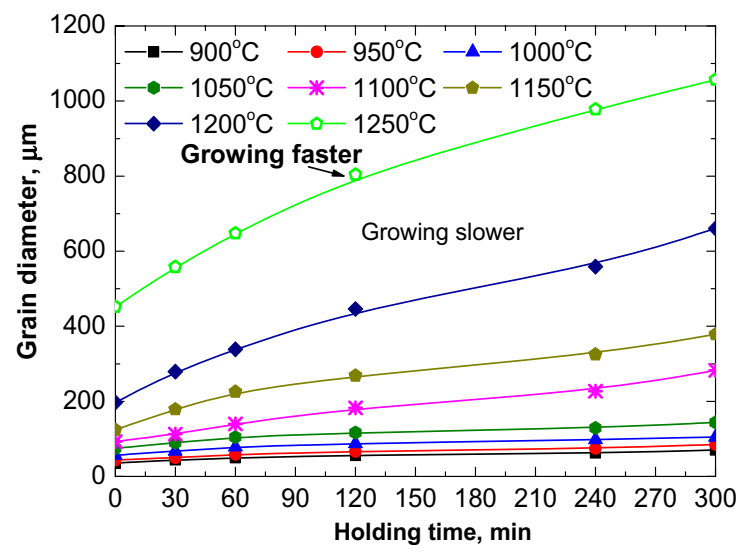

Figure 6. Experimented grain growth at different heating temperatures, with no prior deformation.

\subsection{The mechanism of grain coarsening}

SA508. Gr3 is coarse grained steel. Our prior study has observed that, with no pre-deformation, the grain of the steel grows slowly when temperature is below $1150^{\circ} \mathrm{C}$, but very fast when temperature is beyond that. Figure 6 shows the experimental results. Taking it as reference, we can find that, after small deformation and holding at $1200^{\circ} \mathrm{C}$ for $180 \mathrm{~min}$, the grains grow much faster than the ones with no pre-deformation. Besides, the grains after large deformation (shown in Fig. 4(f), Fig. 5(e) and (f)) grow larger, too. These facts imply that deformation has certain impact on the grain coarsening if the steel is remained in high temperature environment after hot forging.

Since the initial grain size has limited influence on the grain coarsening, the long-time holding at high temperature coupling with inadequate deformation is the main factor promoting the grain coarsening. The reason may lie in the differences of the strain energy in different degree of deformation. 


\section{MATEC Web of Conferences}

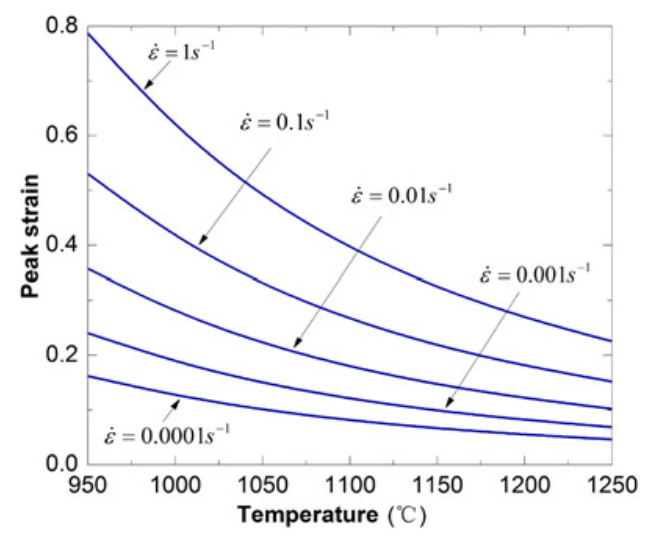

Figure 7. Peak strain at different temperature and strain rates.

When the deformation is small, dynamic recrystallization cannot occur, causing that the strain energy accumulated in the deformation could not be released as much as possible. The remaining strain energy is then contributed to promote grain growth in the following high temperature environment. While, if the strain is enough to cause dynamic recrystallization, the strain energy will be totally or partially consumed, with less energy to promote grain growth. In the small reduction cases, point B receives much larger effective strain than point $\mathrm{A}$ due to non-uniform deformation. With the same reason, the coarsening grain size at point $\mathrm{A}$ is bigger than at point $\mathrm{B}$, because a small amount of local recrystallization may occur at point $\mathrm{B}$ and reduces the driving force for grain growth.

For the sample points where the effective strain is large enough, the dynamic recrystallization can be completely finished, but the fully accumulated strain energy may not be totally released by the recrystallization, and the remained strain energy will take the role as driving force for grain coarsening.

Therefore, in the engineering we have to think about how to avoid the coarsening of grains in the forging deformation. In the heavy forging practice, the effective strain in one hit is usually smaller than the value which may cause grain coarsening after complete dynamic recrystallization, so the coarsening effect of small deformation should be highlighted. It is well known that the peak flow stress is the resultant value of strain hardening and recrystallization softening, so the corresponding peak strain is a critical value to characterize the effect of dynamic recrystallization. Figure 7 shows the peak strain of SA508 Gr.3 steel in different hot deformation condition. In engineering, if the practical effective strain is higher than the corresponding peak stress, the dynamic recrystallization as well as the subsequent meta-dynamic recrystallization will consume the accumulated strain energy and effectively prevent the grain coarsening.

\section{Conclusions}

In this study, the mechanism of grain coarsening of SA508 Gr.3 steel forging is studied. It is concluded that the strain energy takes a critical role in the grain evolution in heavy forging, which will become the driving force for grain coarsening if the deformation is less than a critical value. Peak strain is suggested as an alternative to the critical value. According to the observation, some enlightenment could be proposed for heavy forging. Recrystallization is a key factor to prevent grain coarsening in high temperature environment. Enough strain or deformation is important to guarantee the DRX occur during forging process for the purpose of grain homogenization. And it is necessary to control the finished temperature in finish forging of large parts. 


\section{ICNFT 2015}

This work was financially supported by National Basic Research Program of China (Grant No. 2011CB012903) and National Science and Technology Major Project (Grant No. 2012ZX04012-011).

\section{References}

[1] Y. Tanaka, I. Sato, J. Nuclear. Mat., 417 (2011) 854-859

[2] H. Pous-Romero, H. Bhadeshia, J. Pressure Vessel Technol., 136 (2014) 031402-031402

[3] H. Pous-Romero, H.D.H. Bhadeshia, Metall. and Mat. Trans A, 45 (2014) 4897-4906

[4] Y.-S. Ahn, H.-D. Kim, T.-S. Byun, et al., Nuclear Eng. and Design, 194 (1999) 161-177

[5] T.S. Byun, J.H. Hong, F.M. Haggag, et al. Int. J. Pressure Vessels and Piping, 74 (1997) 231-238

[6] D.S. Sui, F. Chen, P.P. Zhang, Z.S. Cui, J. Iron and Steel Res. Int., 21 (2014) 1022-1029

[7] M. Sun, L. Hao, S. Li, D. Li, Y. Li, J. Nuclear Mat., 418 (2011) 269-280

[8] D. Dong, F. Chen, Z. Cui, Mater. Sci. Eng. A, 634 (2015) 103-115

[9] H. Pous-Romero, I. Lonardelli, D. Cogswell, et al., Mat. Sci. Eng. A, 567 (2013) 72-79

[10] S. Uhm, J. Moon, C. Lee, J. Yoon, B. Lee, ISIJ Int., 44 (2004) 1230-1237 